\title{
Study on the microalgal pigments extraction process: Performance of microwave assisted extraction
}

\author{
Virginie Pasquet ${ }^{\mathrm{a}}$, Jean-René Chérouvrier ${ }^{\mathrm{a}}$, Firas Farhat ${ }^{\mathrm{a}}$, Valérie Thiéry $^{\mathrm{a}}$, Jean-Marie Piot $^{\mathrm{a}}$, Jean- \\ Baptiste Bérard $^{b}$, Raymond Kaas ${ }^{b}$, Benoît Serive ${ }^{b}$, Thierry Patrice ${ }^{c}$, Jean-Paul Cadoret ${ }^{b}$ and Laurent \\ Picot $^{\mathrm{a}, *}$
}

\author{
${ }^{a}$ Université de La Rochelle, UMR CNRS 6250 LIENSs, La Rochelle, 17042, France \\ ${ }^{\mathrm{b}}$ IFREMER Laboratoire PBA, Centre IFREMER de Nantes, Nantes, 44311, France \\ ${ }^{c}$ Département LASER, CHU de Nantes, Nantes, 44093, France
}

* Corresponding author : L. Picot, Tel.: +33 546458220; fax: +33 546458265, email address : Ipicot@univ-Ir.fr

\begin{abstract}
:
The performance of microwaves irradiation (MAE and VMAE) to extract pigments from two marine microalgae was compared to conventional processes (cold and hot soaking and ultrasound-assisted extraction). Pigments were quantified by RP-HPLC and extraction performance was assessed regarding rapidity, reproducibility and extraction yields. Scanning electron microscopy was used at all extraction steps to assess the impact of the process on microalgal cell integrity. Freeze-drying and pigments extraction preserved microalgae cell integrity (except sonication) and evoked agglutination in superposed cells layers. All processes performed on Dunaliella tertiolecta (chlorophyte) lead to rapid pigments extraction, and equivalent pigments extraction yields, the absence of frustule allowing immediate solvent penetration in microalgae cells. In contrast, presence of the frustule in the diatom Cylindrotheca closterium (bacillariophyte) constituted a mechanical barrier to pigment extraction. MAE was identified as the best extraction process for CC pigments as it combined rapidity, reproducibility, homogeneous heating and high extraction yields.
\end{abstract}

Keywords: Pigments; Microalgae; Microwave; Extraction; Chlorophyll; Fucoxanthin; Carotene; MAE; VMAE

Abbreviations: CC, Cylindrotheca closterium; Chl, chlorophyll; DT, Dunaliella tertiolecta; MAE, microwave-assisted extraction; PVDF, poly(vinylidene difluoride); Rt, room temperature; SCF, supercritical fluid; UAE, ultrasound assisted extraction;VMAE, vacuum-microwave assisted extraction 


\section{Introduction}

Marine microalgae constitute one of the most diverse group of oceanic microorganisms, with an estimated $2.10^{5}$ to several millions species [1], from which only 35,000 are described. Extensive screening of cultivated species has lead to the isolation and chemical determination of over 15,000 compounds, including fatty acids, sterols, phenolic compounds, terpenes, enzymes, polysaccharides, alkaloids, toxins and pigments [2]. Because of their high biodiversity and huge productivity, microalgae represent an untapped resource offering great possibilities for the isolation of original natural substances of interest for food, health or biotechnological applications [3, 4]. Their interest also lies in their convenient use as a biotechnological biomass, as they can easily be grown in controlled conditions, handled as conventional lab microorganisms, and genetically modified without any risk of dissemination. Lipids and pigments extraction processes applied to microalgae are mainly derived from phytochemical techniques developed on superior plants and macroalgae. The main parameters driving selection of an extraction technology are biochemical characteristics of extracted molecules, rapidity, limitation of solvent use, reproducibility, extraction yield, selectivity, protection of extracted molecules against chemical transformation, dimension, cost and easiness [5, 6]. Classical organic solvent extraction techniques, including maceration (soaking), percolation, counter-current extraction, pressurized liquid extraction, and soxhlet are widespread technologies described to extract lipids and pigments. These processes are reproducible, allow the rapid extraction of chemicals, but usually imply the use of large amounts of solvents, and the risk of thermal denaturation or transformation of molecules of interest [5]. Coupling steam distillation or hot water extraction with maceration in solvent increases extraction yields for plant essential oils and bioactive compounds [7], but thermolabile molecules are damaged using this technology. The use of enzymes, such as xylanases, pectinases or cellulases, to enhance pigments extractability rates was proposed and validated for superior plants tissues [8,9] and macroalgae [10], and could be of interest for unfrustulated microalgae. Various techniques limiting chemical transformation of pigments have been proposed. Samples can be frozen $\left(-80^{\circ} \mathrm{C}\right.$, liquid nitrogen), freeze-dried, dessicated, or stored in water vapour saturated atmospheres [11] to avoid oxidation and thermal denaturation. Maceration in liquid nitrogen followed by buffer extraction, consisting in pigment precipitation in 50\% ammonium sulphate, was described for the cyanobacterial blue pigment phycocyanin. However subsequent dialysis and gel filtration chromatography steps are needed to desalt pigments solutions [12]. Extraction in aqueous solutions implies a strict control of the $\mathrm{pH}$ as many porphyrin pigments can undergo chemical transformations in acidic or alkaline conditions. For instance, chlorophylls can undergo epimerization, dephytylation and demetallation (pheophytination) [13]. The presence of chlorophyllases in microalgae extracts also explains the rapid degradation of porphyrin pigments $[14,15]$. Changing water to selected solvents, such as sec-butanol, allows a rapid and efficient extraction from plants and microalgae with a good stability of pigments [16]. This solvent can also be favourably used to concentrate pigments extracted with acetone [16]. Hejazi and colleagues proposed a biocompatible strategy to extract carotenoids from Dunaliella salina without killing the cells, using solvents having a Log P (octanol)> 6 [17]. Other cell disruption techniques based on mechanical or osmotic shocks, such as bead beating and ultrasound assisted extraction have been proposed [18]. Mechanical treatments are very drastic, and usually induce thermal denaturation of molecules of interest, especially when using an ultrasonic sharp probe [13]. Osmotic shock may not be efficient when working with frustulated species or armoured dinoflagellates. The use of supercritical carbon dioxide (SCF-CO $\mathrm{CO}_{2}$ ) or combination of solid-phase extraction with SCF-CO $\mathrm{CO}_{2}$ to extract lipids, pigments or bioactive compounds from plants $[19,20]$ or microalgae [21-27] was also described as a very efficient technology, in spite of a high cost. For instance, paprika [28] and Lithospermum pigments are easily and efficiently extracted and purified using $\mathrm{SCF}-\mathrm{CO}_{2}$, in optimized conditions favouring differential solubilization in $\mathrm{CO}_{2}[19]$. 
In the last 10 years, there has been an increased interest in using extraction techniques involving microwaves. MAE and VMAE have been proposed as efficient and rapid processes to extract antioxidants [29] or pigments from plants [30] or spices [19], oils from vegetables [31], allowing reduced solvent consumption and shorter extraction times, with equivalent or higher extraction yields. MAE and VMAE have been applied to marine microalgae to extract lipids [32], and allowed the highest recovery for all tested species compared to autoclaving, bead-beating, sonication or maceration in $10 \% \mathrm{NaCl}$ solution. Choi and colleagues [33] reported the microwave-assisted extraction of astaxanthin from the red yeast Xanthophyllomyces dendrorhous and showed that combining a microwave irradiation to destroy cell walls with a solvent extraction allows a good pigment recovery [33]. Paprika pigments were also efficiently extracted with high yields using microwave irradiation, with a selectivity and efficacy depending on the dielectric constant of the extraction mixture [34]. The combination of sonication and microwaves was studied to extract lipids from vegetables and microalgae sources. Ultrasonication alone, microwave irradiation alone or combination of both techniques gave excellent extraction efficiencies in term of yields and time, with a 10fold reduction in the time needed with conventional methods, and yields increased from 50 to $500 \%$ [31]. The different studies mentioned above suggested that microwaves could be of interest to extract pigments from microalgae. We report here data obtained on the utility and performance of microwave-assisted extraction of pigments from the microalgae Cylindrotheca closterium and Dunaliella tertiolecta, compared to soaking in solvents and ultrasonic extraction.

\section{Experimental}

\subsection{Selection of microalgae species for pigments extraction}

Two model species were studied. Cylindrotheca closterium (CC) belongs to the bacillariophyceae class (diatoms), which covers the most abundant and best known unicellular planktonic algae species. The characteristic feature of diatoms is the presence of a box-like silica wall or frustule surrounding the cell. The frustule is composed of two main components: an outer organic coat, and a complex inner wall made of polymerized hydrated silica [13]. CC is a pennate (pen-shaped) diatom, exhibiting a fusiform shape, with long spines on both ends and a total length of 40 to $90 \mu \mathrm{m}$ [35]. The two main pigments described in $C C$ are chl a and fucoxanthin. Dunaliella tertiolecta (DT) belongs to the chlorophyceae class (green microalgae). Species from the genus Dunaliella exhibit a small ovoid unfrustulated cell $(<20 \mu \mathrm{m})$, covered of cellulose, xylans, mannans and/or glycoproteins, with two equal flagella inserted at the apexes of the cell [13]. Chl $a$, chl $b$ and $\beta, \beta$-carotene are the three major pigments described in $D T$.

\subsection{Microalgae culture, collection and storage}

Microalgae were grown at IFREMER PBA, Nantes. CC strain AC170 (Algo-banque, France) was cultivated in $2.2 \mathrm{~L}$ tubular photobioreactors under constant illumination $\left(120 \mu \mathrm{mol} . \mathrm{m}^{-2} \mathrm{~s}^{-1}\right)$, at $21^{\circ} \mathrm{C}$ in continuous culture maintained in exponential growth phase, with $\mathrm{pH}$ regulation at 7.6, in Walne (Conway) medium diluted in $0.22 \mu \mathrm{m}$ sterile-filtered natural seawater. The CC cell suspension was harvested and cells were separated from culture medium by sedimentation and soft centrifugation $\left(3500 \mathrm{~g}, 15 \mathrm{~min}, 4^{\circ} \mathrm{C}\right.$ ). DT strain CCMP364 (CCMP, USA) was grown in $10 \mathrm{~L}$ flasks under a photoperiode of $16 \mathrm{~h}$ illumination and $8 \mathrm{~h}$ darkness at an average light intensity of $180 \mu \mathrm{mol} . \mathrm{m}^{-2} \mathrm{~s}^{-1}$. Growth was performed at $20^{\circ} \mathrm{C}$, in $\mathrm{pH}$ unregulated batch culture, in Walne (Conway) medium diluted in $0.22 \mu \mathrm{m}$ sterile-filtered natural seawater. The DT cell suspension was harvested at the end of the exponential growth phase, and cells were separated from culture medium by soft centrifugation $(4000 \mathrm{~g}$, $20 \mathrm{~min}, 10^{\circ} \mathrm{C}$ ). Cells were frozen at $-20^{\circ} \mathrm{C}$ and sent to lab LIENSs, La Rochelle. Microalgae were freeze-dried at $-55^{\circ} \mathrm{C}$ and $\mathrm{P}<1 \mathrm{hPa}$, on a freeze-dryer equipped with an HetoLyoPro 
3000 condenser and Heto cooling trap (Therma Electron Corporation, France). All extractions were performed on freeze-dried biomass to calculate extraction yields in micrograms of pigments per mg of dry microalgae.

\subsection{Pigments extraction}

Extractions were performed in triplicate independent assays on $50 \mathrm{mg}$ freeze-dried cells suspended in $30 \mathrm{ml}$ acetone, in a $50 \mathrm{ml}$ Erlenmeyer flask (room temperature (Rt) soaking and $U A E$ ) or in a $100 \mathrm{~mL}$ round bottom glass flask (hot soaking, MAE and VMAE). All extractions were performed in obscurity and under argon atmosphere (except VMAE) to limit chlorophyll photo-oxidation. Rt soaking extractions were performed for 10 to 120 minutes, at $20^{\circ} \mathrm{C}$, under magnetic stirring. Hot soaking extractions were performed in the same conditions at acetone boiling temperature at atmospheric pressure $\left(56^{\circ} \mathrm{C}\right)$, under reflux. Microwave assisted extraction (MAE) and vacuum microwave assisted extraction (VMAE) were performed using a CEM Discovery Microwaves Reactor. For VMAE, the flask was placed in the reactor, connected to a vacuum pump via a condenser (median pressure during $\mathrm{VMAE}=26697 \pm 1144 \mathrm{~Pa}$ ) and microalgae were irradiated for 3 to 15 minutes, at 25 to 100 $W$, under magnetic stirring. Temperature was stabilized at the acetone boiling temperature at VMAE pressure. For MAE the procedure was the same as VMAE, but under atmospheric pressure, at $56^{\circ} \mathrm{C}$. UAE was performed in usual conditions described in most extracting processes, on samples thermostated in an icewater bath, to limit overheating due to the local hot temperature at the tip of the ultrasonic probe. Ultrasounds were continuously applied for 3 to 15 minutes at 4.3 to $12.2 \mathrm{~W}$ (maximal power supplied by the sonicator). Median sample temperature measured at the end of the UAE process was $8.5^{\circ} \mathrm{C}$.

\subsection{Pigments concentration, identification and dosage}

Extracts were filtered onto $0.2 \mu \mathrm{m}$ PVDF membrane filters to remove cells and cell debris that were further characterized by scanning electron microscopy. Pigments solutions were dried using a rotary evaporator under vacuum at $40^{\circ} \mathrm{C}$. The dry extracts were solubilised in 5 $\mathrm{ml}$ acetone for immediate RP-HPLC analysis. The RP-HPLC system was composed of a binary pump (Waters, W600), an autosampler (Waters, W717), a thermostated $\left(20^{\circ} \mathrm{C}\right)$ column compartment, and a photodiode-array detector (Waters, W486). Pigments were separated in triplicate independent assays on a Phenomenex Luna C18 (2) column (250 x $4.6 \mathrm{~mm}, 10 \mu \mathrm{m})$, the mobile phase consisting of a ternary gradient of solvent $A$ (Methanol/water (80/20)); solvent B (Acetonitrile/water (90/10)) and solvent C (ethyl acetate). The gradient flow program was adapted from Jeffrey and collaborators [13], as follows: 0 $\min -100 \%$ A, 3 min-100\% B, 35 min- 30\% B and 70\% C, 38 min-100\% C, 41 min-100\% C, 43 $\min -100 \% \mathrm{~B}, 45 \mathrm{~min}-100 \% \mathrm{~A}$. The flow rate was $1.0 \mathrm{ml} \cdot \mathrm{min}^{-1}$ and pigments elution was monitored at $435 \mathrm{~nm}$. The injection volume was 1 to $50 \mu \mathrm{L}$ for standard pigments and 5 and $10 \mu \mathrm{L}$ for extracts. Pigments were identified on the basis of their retention time compared with standards. The extraction yield for each pigment was calculated using the calibration curve obtained with standards and expressed in $\mu \mathrm{g}$ of pigment per $\mathrm{mg}$ of dry biomass. Performance of the extraction process was assessed calculating pigments extraction yields (chl $a$ and fucoxanthin for $C C$; chl $a$, chl $b$ and $\beta, \beta$-carotene for $D T$ ). As a control to assess the impact of sterilizing filtration on pigment extraction, $50 \mathrm{mg}$ of freeze-dried CC or DT cells were placed on the filtration membranes and pigments were extracted filtrating $30 \mathrm{~mL}$ acetone onto the cells. Samples were dried, solubilized in $5 \mathrm{~mL}$ acetone, and considered as soaking extracts at 0 minute and $20^{\circ} \mathrm{C}$.

\subsection{Scanning electron microscopy (SEM)}

Microalgal cell integrity was studied on freeze-dried cells and after each filtration step following the extraction processes. Cells were placed on a conductive double layer carbon support and examined by scanning electron microscopy using a Philips-FEI Quanta 200 
ESEM/FEG microscope (environmental mode) equipped with a FEG canon delivering 1 to 30 KV beam current.

\subsection{Chemicals and standards}

Acetone, methanol, acetonitrile and ethyl acetate were purchased from Carlo-Erba, France. All solvents used in this study were HPLC grade. $\beta, \beta$-carotene, chl $a$ and chl $b$ were obtained from Sigma Aldrich, France. Fucoxanthin and pheophytin a were obtained from DHI Lab Product, Denmark. Ultra-pure water was obtained using a Milli-Q system (Millipore, France).

\section{Results}

\subsection{Microalgal cell integrity}

SEM observation of $C C$ revealed that cells stuck together and deposited in superposed layers during freeze-drying (Figure 1A, black hyphens). Salt contained in the culture medium also precipitated as white clusters associated to cells layers (Figure 1A, white arrows). Pigments extraction steps had no effect on cell integrity, except in the case of UAE, that destroyed cells and induced the formation of a homogeneous cell paste (Figure 1D). SEM observation of $D T$ cells revealed that freeze-drying conserved the cell shape and induced flattening into confluent homogeneous layers (Figure 2A). Pigments extraction processes had no influence on cell shape, except sometimes junction of neighbour cell membranes or conglomeration of cell debris between cell membranes.

\subsection{Pigments content}

Figure 3 presents the chromatograms obtained after $C C$ and $D T$ pigments extraction by $\mathrm{Rt}$ soaking in acetone. As expected, chl $a$ and fucoxanthin were the two major pigments detected in $C C$ extracts at $435 \mathrm{~nm}$. $\beta, \beta$-carotene and pheophytin a were present in a too weak concentration to be dosed accurately by peak integration on chromatograms. Chl $a$, chl $b$ and $\beta, \beta$-carotene were identified as the three major pigments in $D T$ extracts. As expected, no fucoxanthin was detected in $D T$ chromatograms. The peaks identified by a retention time between 17 and 23 min corresponded to minor xanthophylls described in DT (neoxanthin, violaxanthin and lutein).

\subsection{Pigments extraction yields and kinetics, pigments degradation}

\subsubsection{Cold and hot soaking}

Pigment extraction from $C C$ was time-dependent at Rt and the yield increased steadily (Figure 4A). The best yields were obtained after 60 minutes for chl a $\left(7.48 \pm 0.21 \mu \mathrm{g} \cdot \mathrm{mg}^{-1}\right)$ and 120 minutes for fucoxanthin $\left(5.34 \pm 0.06 \mu \mathrm{g} \cdot \mathrm{mg}^{-1}\right)$. Degradation of chl a after $60 \mathrm{~min}$ was obvious as the yield of chl a recovered after 120 min was lower than that at $60 \mathrm{~min}$. In contrast, no fucoxanthin degradation was measured, indicating a good stability in the extraction conditions. DT soaking in acetone at Rt allowed a rapid extraction of chl $a$, chl $b$ and $\beta, \beta$-carotene (Figure $4 \mathrm{C}$ ). The maximal extraction yields were reached instantaneously for chl $b$ and $\beta, \beta$-carotene $\left(1.50 \mu \mathrm{g} \cdot \mathrm{mg}^{-1}\right.$ and $1.20 \mu \mathrm{g} \cdot \mathrm{mg}^{-1}$ respectively), and after 10 minutes for chl a $\left(4.60 \mu \mathrm{g} \cdot \mathrm{mg}^{-1}\right)$. Heating the soaking suspension accelerated pigments extraction as most $C C$ pigments were extracted in 30 minutes, with a higher extraction yield for chl $a$ in twice as less time $\left(9.31 \pm 0.44 \mu \mathrm{g} \cdot \mathrm{mg}^{-1}\right.$ in $\left.30 \mathrm{~min}\right)$, and an equivalent yield in twice as less time for fucoxanthin $\left(5.23 \pm 0.06 \mu \mathrm{g} \cdot \mathrm{mg}^{-1}\right.$ in $\left.60 \mathrm{~min}\right)$ (Figure 4B). However, heating the soaking suspension evoked chl a degradation in $C C$ and $D T$ beyond $30 \mathrm{~min}$ as demonstrated by the decrease of extraction yields (CC, Figure 4B; $D T$, data not shown). 


\subsubsection{Microwaves-assisted extraction at atmospheric pressure (MAE)}

MAE of CC at $50 \mathrm{~W}$ (Figure $5 \mathrm{~A}$ ) allowed total extraction of fucoxanthin in 3 to 5 min, with a maximal extraction yield $\left(4.24 \pm 0.09 \mu \mathrm{g} \cdot \mathrm{mg}^{-1}\right)$, equivalent to the yield obtained after $60 \mathrm{~min}$ Rt soaking $\left(4.68 \pm 0.10 \mu \mathrm{g} \cdot \mathrm{mg}^{-1}\right)$ or hot soaking $\left(5.23 \pm 0.06 \mu \mathrm{g} \cdot \mathrm{mg}^{-1}\right)$. Increasing irradiation time or power had no impact on the fucoxanthin extraction yield, demonstrating that all extractable fucoxanthin was recovered in $5 \mathrm{~min}$ and not damaged by microwave irradiation. The highest chl a extraction yield was reached after only 5 min of MAE $\left(8.65 \pm 0.29 \mu \mathrm{g} \cdot \mathrm{mg}^{-1}\right)$ when $60 \mathrm{~min}$ and $30 \mathrm{~min}$ were respectively necessary for Rt soaking $\left(7.48 \pm 0.21 \mu \mathrm{g} \cdot \mathrm{mg}^{-1}\right)$ and hot soaking $\left(9.31 \pm 0.44 \mu \mathrm{g} \cdot \mathrm{mg}^{-1}\right)$. Increasing irradiation time beyond $5 \mathrm{~min}$, as well as increasing irradiation power to values superior to $50 \mathrm{~W}$, lead to chl a degradation as indicated by the drastic decrease of extraction yields (Figure 5B). As expected, MAE performed at $50 \mathrm{~W}$ on $D T$ allowed instantaneous extraction of pigments (Figure 6).

\subsubsection{Vacuum Microwaves-Assisted Extraction (VMAE)}

Figure 7 present the VMAE of chl a and fucoxanthin from CC. VMAE allowed a rapid extraction of fucoxanthin and chl a (best extraction yields measured after 5 min irradiation). As observed with MAE, increasing the irradiation power beyond $75 \mathrm{~W}$ resulted in chl a degradation. VMAE was less efficient than MAE to extract chl a and fucoxanthin, as increasing the irradiation power to $75 \mathrm{~W}$ did not allow to obtain equivalent extraction yields (chl a: $5.25 \pm 0.04 \mu \mathrm{g} . \mathrm{mg}^{-1}$ for VMAE and $8.65 \pm 0.29 \mu \mathrm{g} \cdot \mathrm{mg}^{-1}$ for MAE; fucoxanthin : $3.68 \pm$ $0.05 \mu \mathrm{g} \cdot \mathrm{mg}^{-1}$ for VMAE and $4.24 \pm 0.09 \mu \mathrm{g} \cdot \mathrm{mg}^{-1}$ for MAE). VMAE performed at $50 \mathrm{~W}$ induced instantaneous extraction of $D T$ pigments (Figure 6).

\subsubsection{UAE}

Figure 8 and 6 present the UAE performed on CC and DT respectively. Sonication of $C C$ at $12.2 \mathrm{~W}$ (maximal power supplied by the sonicator) and $8.5^{\circ} \mathrm{C}$ under atmospheric pressure allowed a maximal extraction of fucoxanthin in 3 to $10 \mathrm{~min}$, with an extraction yield (4.49 \pm $\left.0.08 \mu \mathrm{g} \cdot \mathrm{mg}^{-1}\right)$ in the range of values obtained by Rt soaking for $60 \mathrm{~min}\left(4.68 \pm 0.10 \mu \mathrm{g} \cdot \mathrm{mg}^{-1}\right)$ or MAE for $5 \mathrm{~min}\left(4.24 \pm 0.09 \mu \mathrm{g} \cdot \mathrm{mg}^{-1}\right)$. Extraction of chlorophyll a was also maximal after 3 to 10 min sonication, but with an extraction yield of $4.95 \pm 0.27 \mu \mathrm{g} \cdot \mathrm{mg}^{-1}$, much lower than the values obtained by the other processes (Rt soaking in acetone for $60 \mathrm{~min}: 7.48 \pm 0.21$ $\mu \mathrm{g} . \mathrm{mg}^{-1}$; hot soaking in acetone for $30 \mathrm{~min}: 9.31 \pm 0.44 \mu \mathrm{g} \cdot \mathrm{mg}^{-1}$; MAE : $8.65 \pm 0.29 \mu \mathrm{g} \cdot \mathrm{mg}^{-1}$; VMAE : $\left.5.25 \pm 0.04 \mu \mathrm{g} . \mathrm{mg}^{-1}\right)$. Variability of the extraction yields of fucoxanthin and chlorophyll a was important between each extraction assay, as demonstrated by important errors bars on Figure 8. UAE performed on DT cells induced instantaneous extraction of $D T$ pigments with yields equivalent to the other processes (Figure 6).

\section{Discussion}

In this study, acetone was chosen as a model extraction solvent as it extracts most photosynthetic pigments, in a wide range of polarity, and acetone $90 \%$ is recommended for phytoplankton pigment analysis [13, 36, 37]. However, pigment extraction was performed in acetone $100 \%$ to limit chl a hydrolysis by the thylakoid-bound enzyme chlorophyllase, present in most diatom species and chlorophyceae [38], activated during extraction even before solvent extraction (cell harvesting and filtration), and still active to a small extent in $90 \%$ acetone $[14,39]$. Chlorophyllase activity was previously reported to be low in CC, with 0 to $5 \%$ chlorophyllide a formed as percentage of total chl a when pigment extraction was performed in $50 \%$ acetone at $20^{\circ} \mathrm{C}$, and high in $D T$, with 12 to $79 \%$ chlorophyllide a formed in the same conditions [38]. The good extraction yields obtained in acetone allowed a relevant comparison of the processes performances, in spite of absence of selectivity. In order to improve selectivity of the process towards a selected pigment, MAE and VMAE could be 
performed in others solvents allowing a more selective solubilization of apolar (chlorophylls, carotens) or polar (xanthophylls, phycobiliproteins) pigments. Also, MAE and VMAE could be performed in mixtures of different solvents, in solvents authorized by regulations to extract pigments for nutritional purposes (e.g. carotenoids), or in apolar solvents such as hexane mixed with weflon ${ }^{\circledR}$.

This study suggests that microwaves-assisted processes have weak utility for pigments extraction from species lacking frustule and thick outer exopolysaccharide envelope, as conventional techniques exhibit equivalent efficiency in term of yields, rapidity and protection of extracted molecules against chemical transformation. It seems indeed that freeze-drying is sufficient to weaken the cell membrane and access pigments for solvent solubilization in these species. In contrast, MAE is very efficient when a mechanical resistance such as frustule in diatoms limits solvent access into the cells. In this view, MAE could also be useful to extract pigments from unfrustulated microalgae synthesizing a thick exopolysaccharide envelope, such as species from the genus Porphyridium, or from armoured species dinoflagellates for which pigments extraction is very difficult [13]. Compared to conventional extraction methods, the use of microwaves accelerated diatom pigments extraction kinetics, as extraction yields usually reached after 30 to 60 minutes using Rt and hot soaking were obtained in a few minutes using MAE. This excellent result suggests that high extraction yields could still be obtained increasing the ratio biomass/solvent, thus limiting the volume of solvent to be handled. The fact that MAE and VMAE are very fast extraction processes performed in highly controlled temperature conditions probably accounts for pigments protection from chemical transformation. Also, we observed that pigments extraction yields and reproducibility of the process were strongly dependent upon temperature regulation in the extraction medium. Compared to conventional processes, microwaves-assisted extraction processes offer the advantage of a homogeneous thermoregulation of the medium, as no heat transfers are required to heat cells located in the center of the flask, and no hot spots exist as in UAE. Microalgal organites are also homogeneously heated, allowing synchronous pigments extraction, whatever their subcellular localization (cytoplasmic or chloroplastic). In this study, no degradation of fucoxanthin was observed during microwave irradiation or hot extraction at $56^{\circ} \mathrm{C}$, and the degradation of other minor xanthophylls was not studied. Degradation of carotenoids during microwave heating usually starts at temperatures superior to $60^{\circ} \mathrm{C}$ for the most thermosensitive molecules (violaxanthin and antheraxanthin) while provitamin A carotenoids ( $\beta$-carotenes, $\alpha$-carotenes and $\beta$-cryptoxanthin) as well as lutein are more heat-stable [40-42]. It can thus be considered that MAE temperature should not exceed $60^{\circ} \mathrm{C}$ to ensure carotenoids extraction in non-denaturating conditions. Assessment of the frustule integrity after MAE and VMAE demonstrated that microwave irradiation did not evoke frustule disruption as observed in UAE. Microwaves-assisted processes can thus be considered as a "clean" processes inducing frustule permabilization but avoiding frustule explosion. MAE presents the advantage of allowing fast and efficient pigment extraction without the need of high pressures to obtain important yields, as in SCF processes, which however have also the high interest of allowing pigments extraction in toxic solvent-free medium. Considering that efficiency of a pigment extraction process depends upon its selectivity, rapidity, yield, reproducibility, and protection of extracted molecules against chemical transformation, MAE appears as a relevant and innovative process to extract pigments in labs studying photosynthetic pigments or performing routine spectrofluorimetric or spectrophotometric pigments dosages. Also, the development of microwaves pilot units and industrial microwaves reactors allows to consider a possible use of MAE to extract pigments of interest at industrial scale or in particular conditions (e.g. oceanographic ships sampling seawaters), overcoming the limits of traditional techniques in term of quality or profitability of the extracts. This first study on the performance of microwaves-assisted processes to extract major pigments from frustulated and unfrustulated microalgae suggests that optimizing the extraction parameters may be necessary to efficiently purify selected pigments present in a particular species. It will be of interest to establish whether microwaves-assisted processes have also interest to extract minor pigments present in microalgae and other pigments present in various marine organisms. 


\section{Conclusive remarks}

The freeze-drying process and pigments extraction steps preserved microalgae cell integrity and evoked agglutination in superposed layers, except UAE. Subsequently the success of pigments extraction from freeze-dried microalgae may mostly depend on solvent diffusion across the cells, pigments solubility, and thermodynamical parameters. Acetone extracted all major and minor pigments described in the two microalgae species, in a wide range of polarity. Cold soaking was a time-consuming process to extract pigments from the model diatom CC, did not allow a total extraction and induced chl a degradation. In contrast, cold soaking was efficient, simple and rapid to extract pigments from the model chlorophyte $D T$, demonstrating that the use of more sophisticated processes are unnecessary. All other assays performed on $D T$ confirmed that the absence of frustule allowed a fast and efficient solvent penetration and pigment extraction, whatever the extraction process studied. The absence of colour of $D T$ cells and cell debris after filtration on PVDF membranes, confirmed that $D T$ pigments extraction in acetone was total. Heating the soaking suspension accelerated CC pigments extraction, allowed a total extraction but was damaging for chl a after $30 \mathrm{~min}$. The differences observed in between Rt and hot soaking extraction yields demonstrate that temperature is a crucial parameter determining the yield of microalgal pigment extraction. It is then important to accurately define the highest extraction temperature allowing a rapid extraction with high yields, without however damaging thermolabile pigments such as chl a. MAE drastically accelerated CC pigments extraction, and did not damage chl $a$ if a short ( $\leq 5 \mathrm{~min})$ and weak irradiation ( $\leq 50 \mathrm{~W}$ ) was applied. In our conditions, MAE was considered as the best extraction process, as it combined rapidity, efficiency and protection against thermal denaturation. VMAE allowed a rapid and efficient extraction of chl a and fucoxanthin from $C C$, at moderate irradiation power $(75 \mathrm{~W})$, and was not degradative for chl a in soft conditions. However, it did not allow to reach extraction yields obtained with MAE, and was technically more complex than MAE as vacuum was needed. Except pressure, the main difference between VMAE and MAE was temperature, VMAE being performed at $22^{\circ} \mathrm{C}$ and $\mathrm{MAE}$ at $56^{\circ} \mathrm{C}$. It is then obvious that a higher temperature favours pigments extraction, whatever the process considered, as long as pigments are not damaged. In spite of high extraction yields, the repeatability of UAE was insufficient to define a relevant and reproducible pigment extraction process. The weak chl a extraction yield obtained by UAE of $C C$ was probably due to an insufficient extraction power in our conditions, as the high chl a extraction yield obtained after 5 min sonication of $D T$ invalidated the hypothesis of chl a thermal degradation at the tip of the sonication probe.

\section{Acknowledgements}

We acknowledge Monique Bordes for supervising the scanning electron microscopy study at the "Centre Commun d'Analyse" at La Rochelle University. We are grateful to the "Comité de Charente-Maritime de la Ligue contre le cancer" for financial support and to "La Ligue Nationale contre le Cancer" for VP's PhD grant.

\section{Abbreviations}

$\begin{array}{ll}\text { CC } & \text { Cylindrotheca closterium } \\ \text { Chl } & \text { Chlorophyll } \\ \text { DT } & \text { Dunaliella tertiolecta } \\ \text { MAE } & \text { Microwave-Assisted Extraction }\end{array}$




$\begin{array}{ll}\text { PVDF } & \text { Poly(vinylidene difluoride) } \\ \text { Rt } & \text { Room temperature } \\ \text { SCF } & \text { Supercritical fluid } \\ \text { UAE } & \text { Ultrasound Assisted Extraction }\end{array}$

VMAE Vacuum-Microwave Assisted Extraction

\section{Figures}

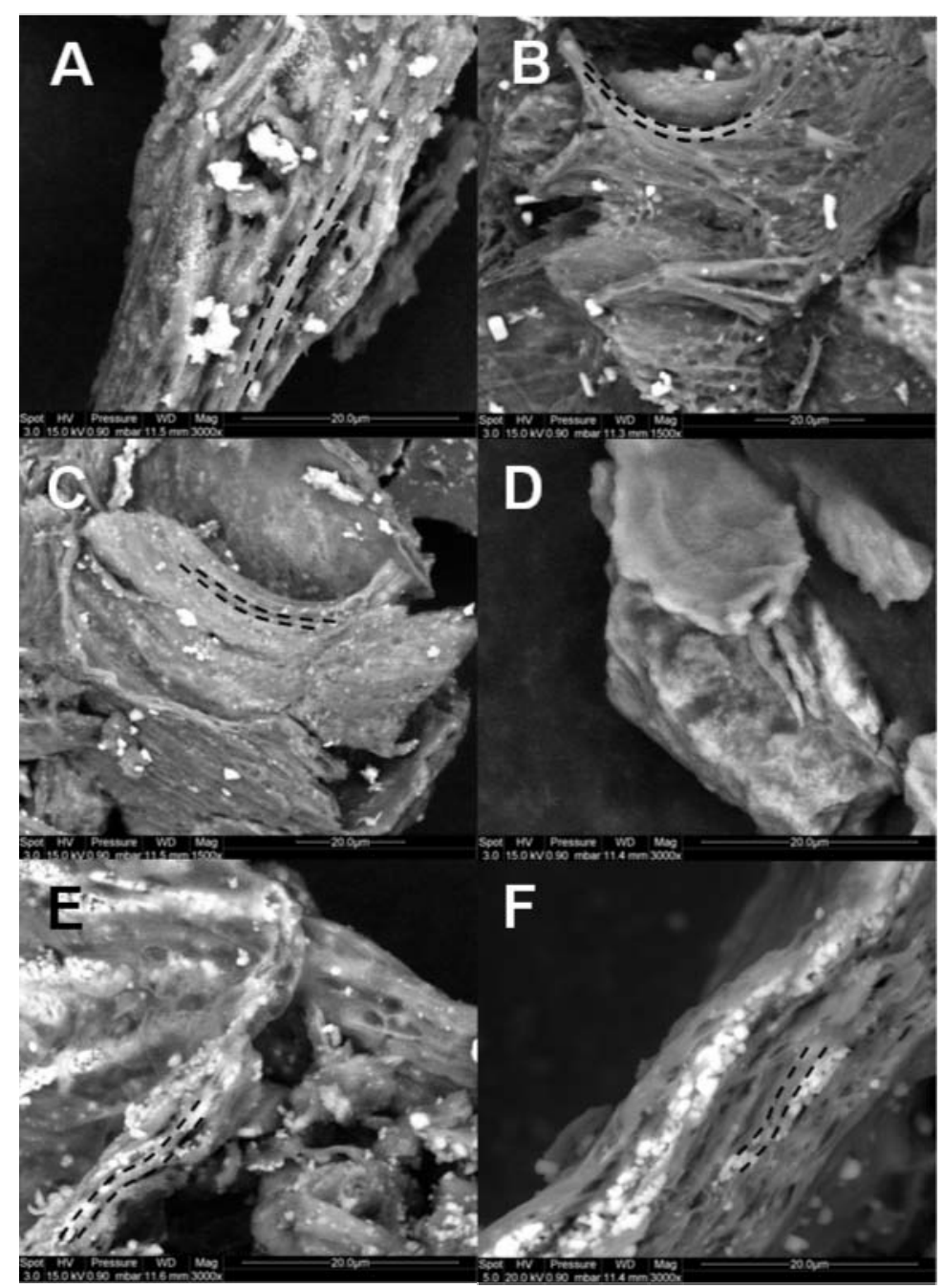

Figure 1. SEM observation of $C C$ after freeze-drying $(A)$ or freeze-drying followed by hot soaking (B), Rt soaking (C), UAE (D), MAE (E), or VMAE (F). Salt crystals formed during $\mathrm{pH}$ regulation of the cell culture medium and precipitated during freeze-drying and pigment extractions were observed in most CC samples (white arrows). Black hyphens underline the layers formed by $C C$ cells accumulation. 


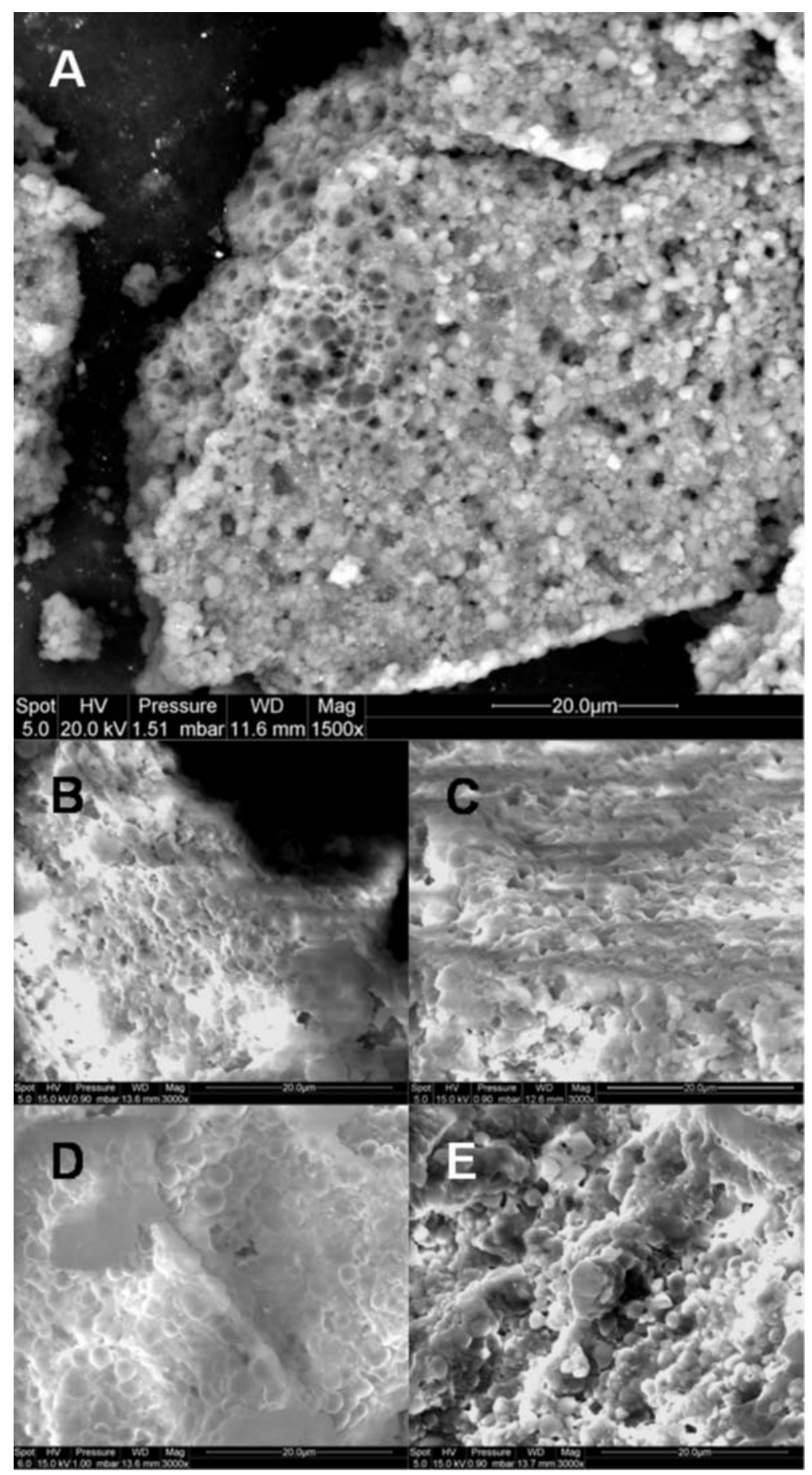

Figure 2. SEM observation of $D T$ after freeze-drying $(A)$ or freeze-drying followed by Rt soaking (B), UAE (C), MAE (D), or VMAE (E). Cells flattening into confluent homogeneous layers were observed in all samples. 

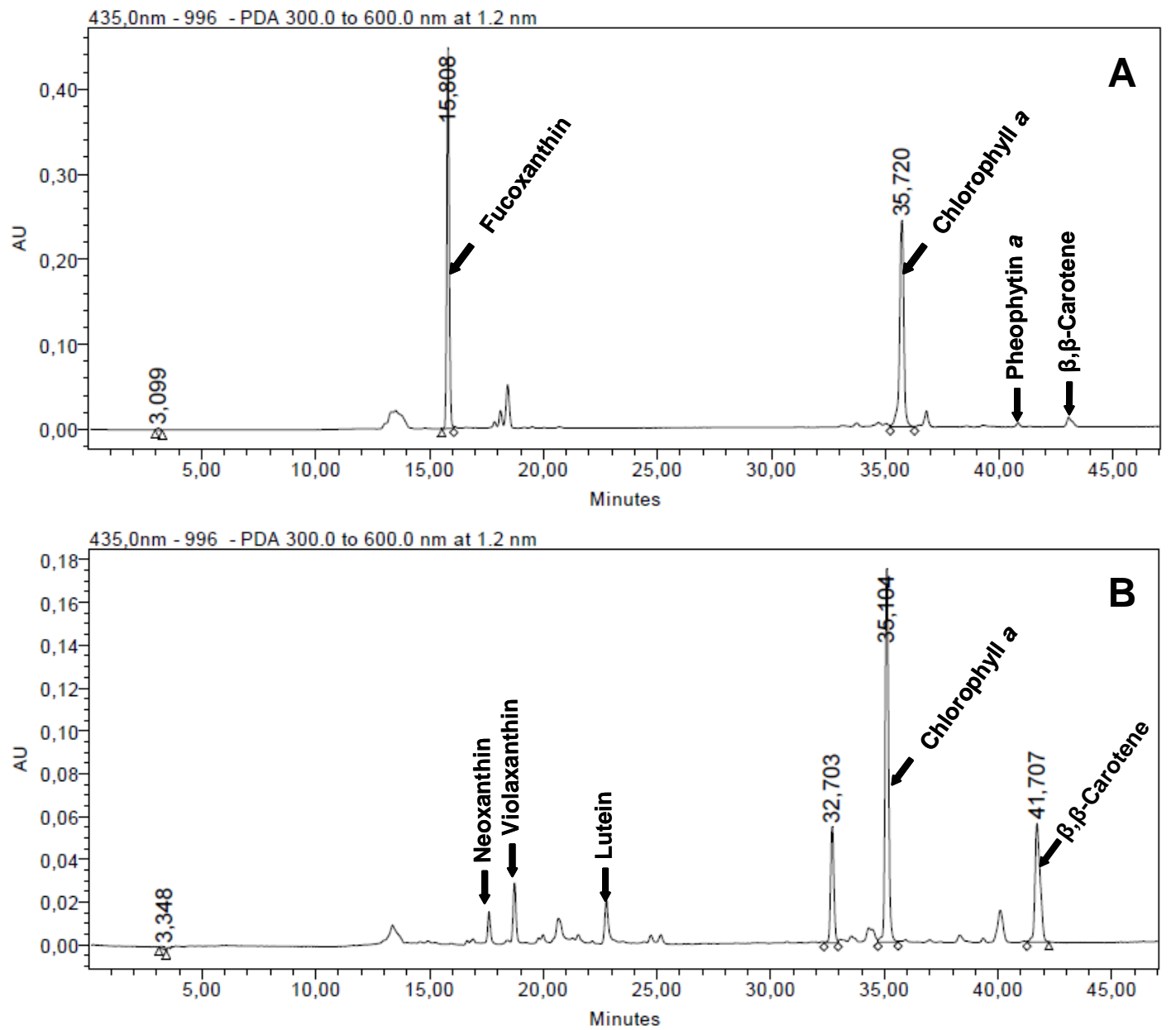

Figure 3. RP-HPLC chromatograms at $435 \mathrm{~nm}$ of acetone extracts of $C C(\mathrm{~A})$ and $D T(\mathrm{~B})$. For each species, identical chromatograms were obtained, whatever the pigment extraction process used (data not shown).
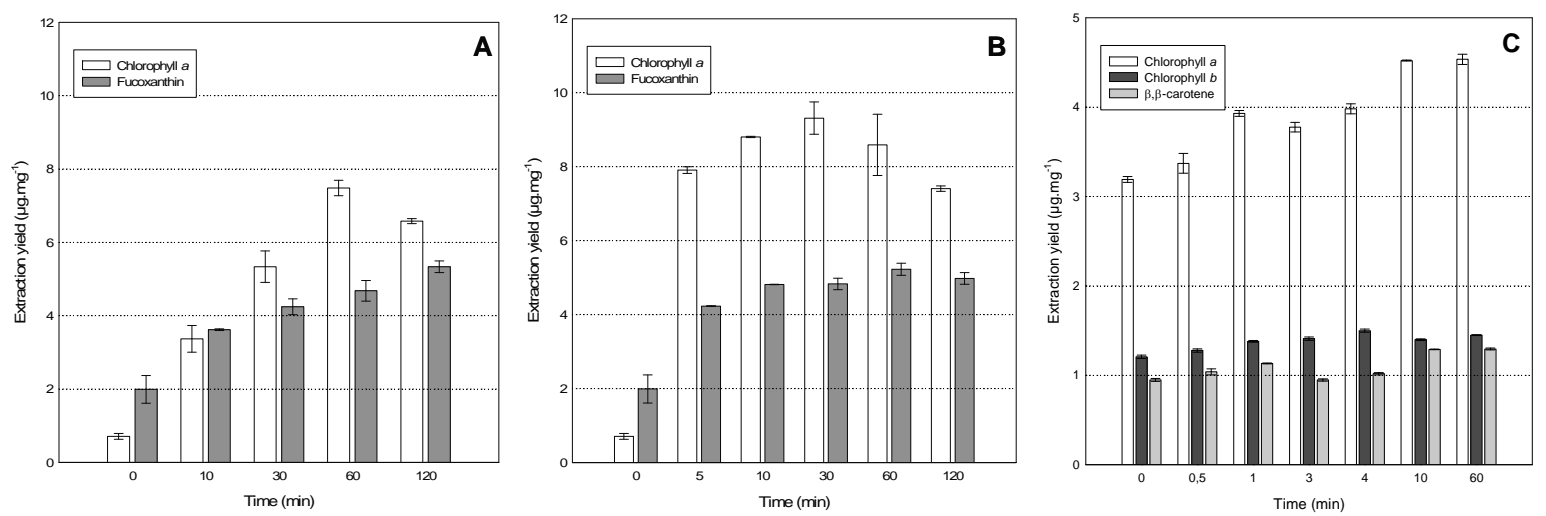

Figure 4. Pigments extraction kinetics. Rt soaking of $C C$ cells (A), hot soaking of $C C$ cells (B) and

$\mathrm{Rt}$

soaking of

$D T$ cells 

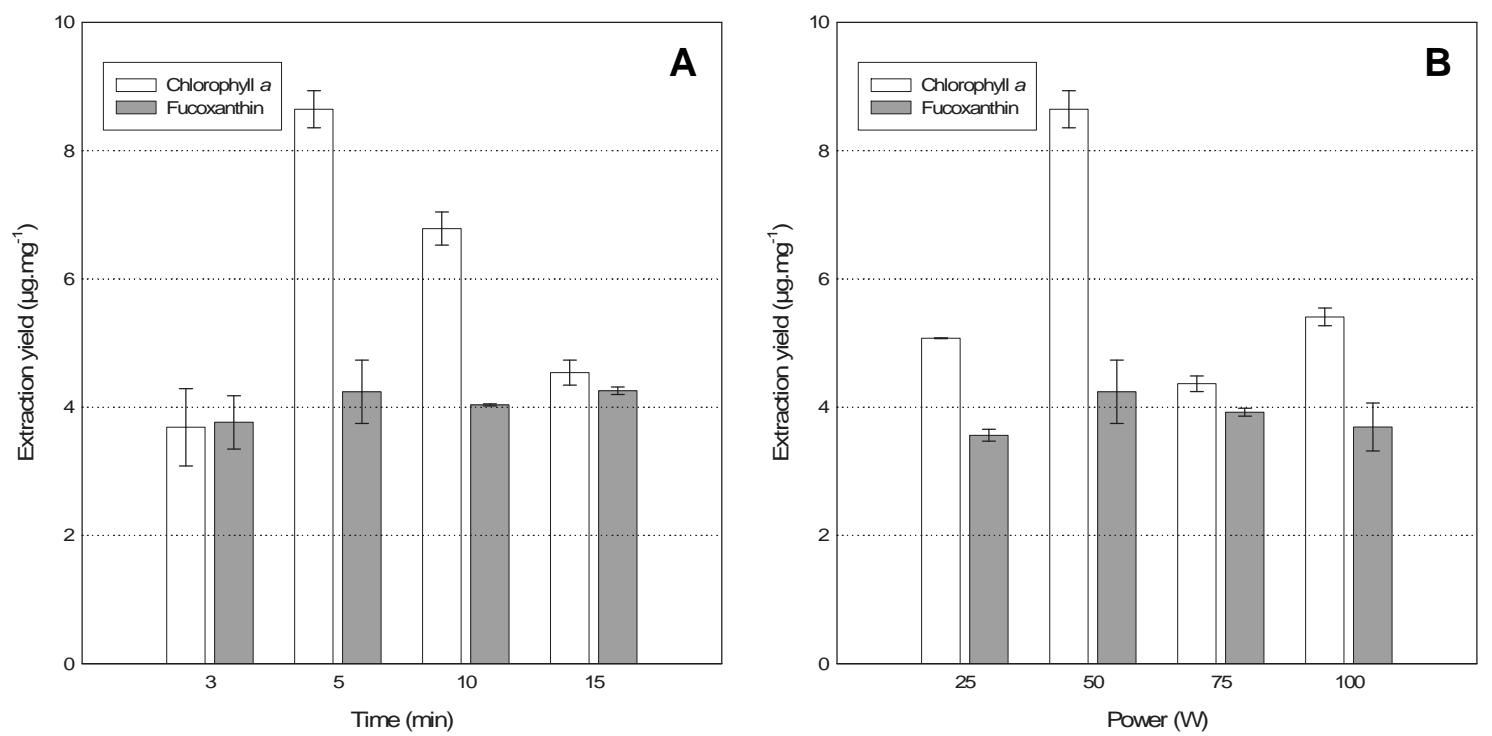

Figure 5. Influence of MAE duration (power $=50 \mathrm{~W}$ ) and irradiation power (duration= $5 \mathrm{~min}$ ) on the extraction yields of $C C$ pigments.

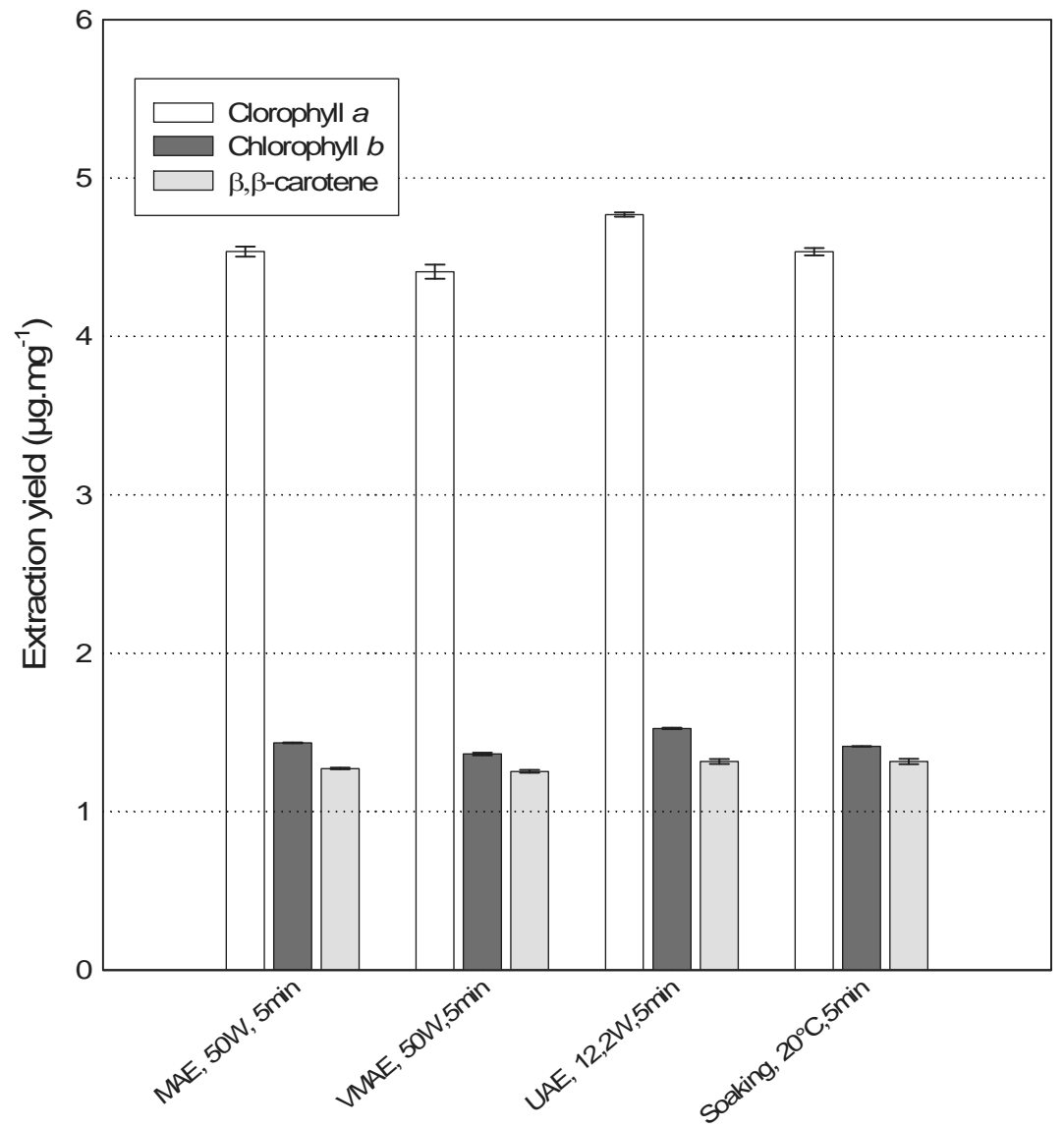

Figure 6. Comparison of $D T$ pigments extraction yields obtained with MAE, VMAE, .UAE and cold soaking. 

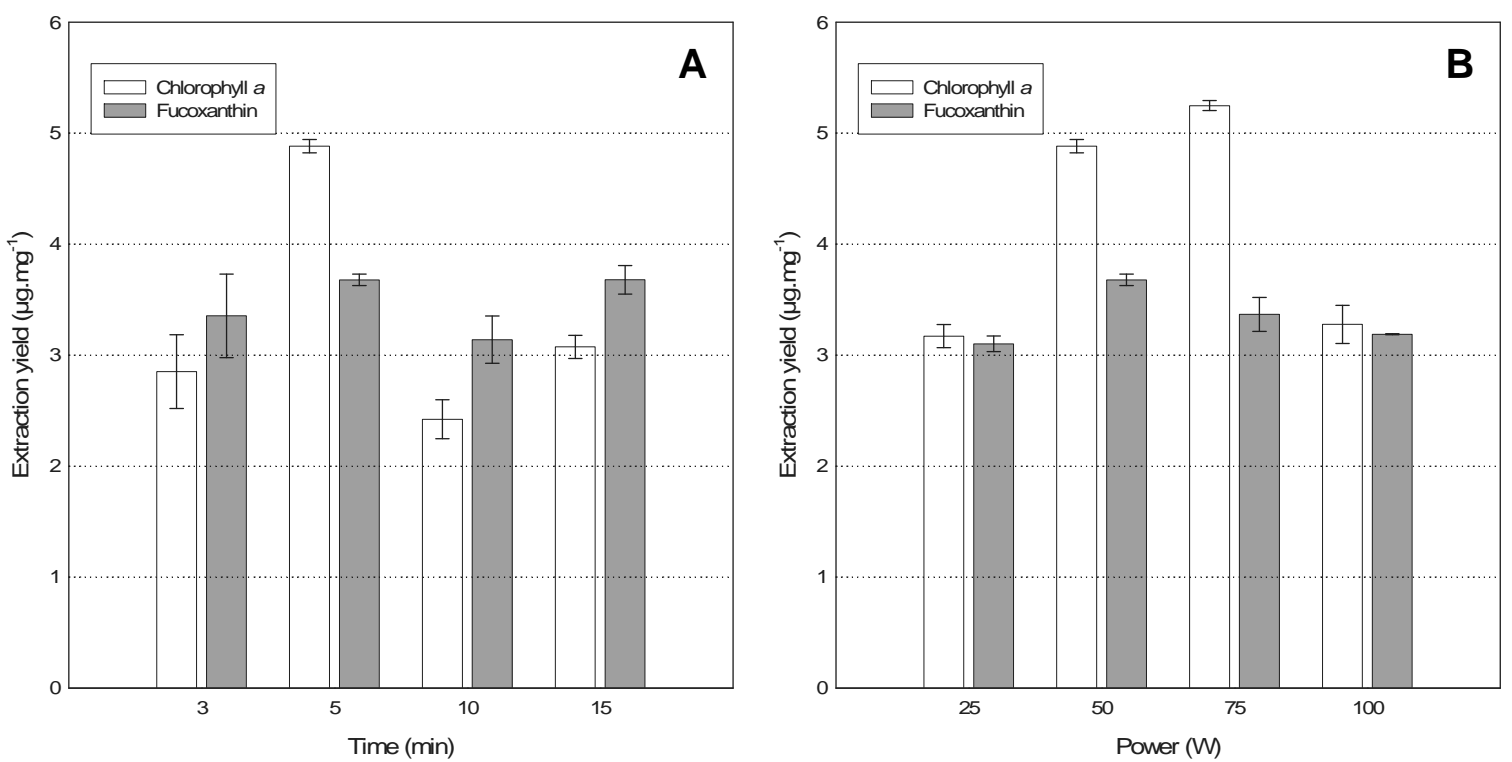

Figure 7. Influence of VMAE duration (power $=50 \mathrm{~W}$ ) and irradiation power (duration= $5 \mathrm{~min}$ ) on the extraction yields of $C C$ pigments.
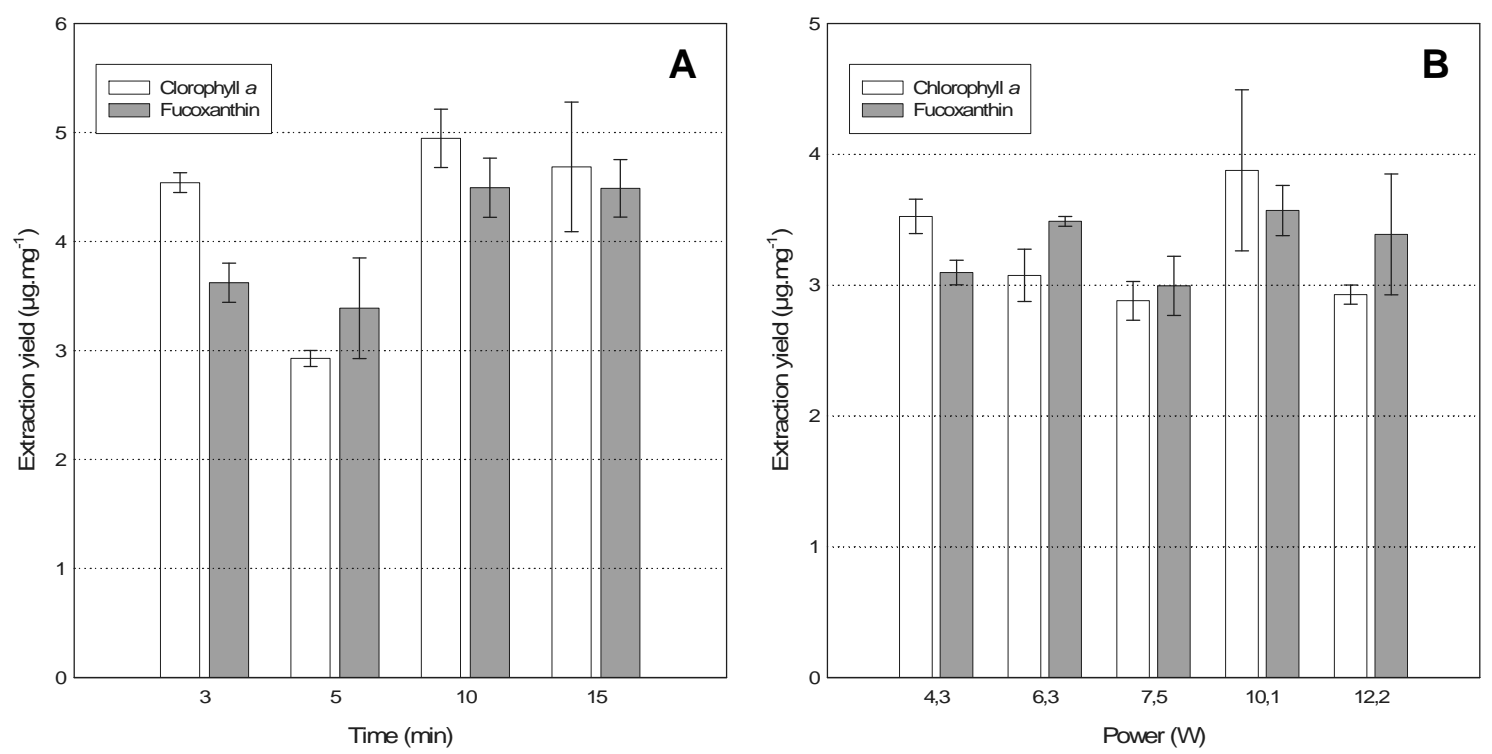

Figure 8. Influence of UAE duration (power $=12.2 \mathrm{~W}$ ) and irradiation power (duration= $5 \mathrm{~min}$ ) on the extraction yields of $C C$ pigments. 


\section{References}

[1] Cadoret JP, Bernard O. Lipid biofuel production with microalgae: potential and challenges. J Soc Biol 2008; 202(3): 201-211.

[2] Kornprobst JM. Substances naturelles d'origine marine. Eds Lavoisier Technique et documentation, 2005. (soon published in English as the Encyclopedia of Marine Natural Products, Wiley Blackwell Eds.)

[3] Bourguet-Kondracki ML, Kornprobst JM. Marine pharmacology: Potentialities in the treatment of infectious diseases, osteoporosis and Alzheimer's disease. Adv Biochem Eng/Biotechnol 97; 2005 : 105-131.

[4] Cardozo KHM, Guaratini T, Barros MP, Falcão VR, Tonon AP, Lopes NP, Campos S, Torres MA, Souza AO, Colepicolo P, Pinto E. Metabolites from algae with economical impact. Comp Biochem Pysiol Part C: Toxicol Pharmacol 2007; 146: 60-78.

[5] Wang L, Weller CL. Recent advances in extraction of nutraceuticals from plants. Trends Food Sci Technol 2006; 17: 300-312.

[6] Rodríguez-Bernaldo de Quirós A, Costa HS. Analysis of carotenoids in vegetable and plasma samples: A review. J Food Compos Anal 2006; 19: 97-111.

[7] Manzan ACCM, Toniolo FS, Bredow E, Povh NP. Extraction of essential oil and pigments from Curcuma longa $(L)$ by steam distillation and extraction with volatile Solvents. J Agric Food Chem 2003; 51: 6802-6807.

[8] Kim DH, Kim JH, Bae SE, Seo JH, Oh TK, Lee CH. Enhancement of natural pigment extraction using Bacillus species xylanase. J Agric Food Chem 2005; 53: 2541-2545.

[9] Choudhari SM, Ananthanarayan L. Enzyme aided extraction of lycopene from tomato tissues. Food Chem 2007; 102: 77-81.

[10] Deniaud E, Fleurence J, Lahaye M. Preparation and chemical characterization of cell wall fractions enriched in structural proteins from Palmaria palmata (Rhodophyta). Bot Mar 2003; 46: 366-377.

[11] Esteban R, Balaguer L, Manrique E, Rubio de Casas R, Ochoa R, Fleck I, PintoMarijuan M, Casals I, Morales D, Jiménez MS, Lorenzo R, Artetxe U, Becerril JM, Garcia-Plazaola JI. Alternative methods for sampling and preservation of photosynthetic pigments and tocopherols in plant material from remote locations. Photosynth Res 2009; 101: 77-88.

[12] Sachindra NM, Bhaskar N, Mahendrakar NS. Carotenoids in crabs from marine and fresh waters of India. LWT Food Sci Technol 2005; 38: 221-225.

[13] Jeffrey SW, Mantoura RFC, Wright SW. Phytoplankton pigments in oceanography, Guidelines to Modern Methods, 1997, Eds UNESCO.

[14] Barrett J, Jeffrey SW. Chlase and formation of an atypical chlide in marine algae. Plant Physiol 1964; 33: 911-917.

[15] Karboune S, Neufeld R, Kermasha S. Immobilization and biocatalysis of chlase in selected organic solvent systems. J Biotechnol 2005; 120: 273-283.

[16] Martinson TA, Plumley FG. One-step extraction and concentration of pigments and acyl lipids by sec-butanol from in vitro and in vivo samples. Anal Biochem 1995; 228: 123130.

[17] Hejazi MA, De Lamarliere C, Rocha JMS, Vermuë M, Tramper J, Wijffels RH. Selective extraction of carotenoids from the microalga Dunaliella salina with retention of viability. Biotechnol Bioeng 2002;79: 29-36.

[18] Rostagno MA, Palma M, Barroso CG. Ultrasound-assisted extraction of isoflavones from soy beverages blended with fruit juices. Anal Chim Acta 2007; 597: 265-272.

[19] Jaren-Galan M, Nienaber U, Schwartz SJ. Paprika (Capsicum annuum) oleoresin extraction with supercritical carbon dioxide. J Agric Food Chem 1999; 47: 3558-3564.

[20] Kim W-J, Kim J-D, Kim J, Oh S-G, Lee Y-W. Selective caffeine removal from green tea using supercritical carbon dioxide extraction. J Food Eng 2008; 89: 303-309. 
[21] Macías-Sánchez MD, Mantell C, Rodríguez M, Martínez de la Ossa E, Lubián LM, Montero O. Supercritical fluid extraction of carotenoids and chl a from Nannochloropsis gaditana. J Food Eng 2005; 66: 245-251.

[22] Macías-Sánchez MD, Mantell C, Rodríguez M, Martínez de la Ossa E, Lubián LM, Montero O. Supercritical fluid extraction of carotenoids and chl a from Synechococcus sp. J Supercrit Fluids 2007; 39: 323-329.

[23] Macías-Sánchez MD, Mantell C, Rodríguez M, Martínez de la Ossa E, Lubián LM, Montero O. Comparison of supercritical fluid and ultrasound-assisted extraction of carotenoids and chl a from Dunaliella salina. Talanta 2009; 77: 948-952.

[24] Macías-Sánchez MD, Serrano CM, Rodríguez MR, Martínez de la Ossa E. Kinetics of the supercritical fluid extraction of carotenoids from microalgae with $\mathrm{CO}_{2}$ and ethanol as cosolvent. Chem Eng J 2009; 150: 104-113.

[25] Mendes RL, Nobre BP, Cardoso MT, Pereira AP, Palavra AF. Supercritical carbon dioxide extraction of compounds with pharmaceutical importance from microalgae. Inorg Chim Acta 2003; 356: 328-334.

[26] Klejdus B, Kopecký J, Benesová L, Vacek J. Solid-phase/supercritical-fluid extraction for liquid chromatography of phenolic compounds in freshwater microalgae and selected cyanobacterial species. J Chromatogr A 2009; 1216: 763-771.

[27] Mendiola JA, Jaime L, Santoyo S, Reglero G, Cifuentes A, Ibañez E, Señoráns FJ. Screening of functional compounds in supercritical fluid extracts from Spirulina platensis. Food Chem 2007; 102:1357-1367.

[28] Rutkowska J, Stolyhwo A. Application of carbon dioxide in subcritical state $\left(\mathrm{LCO}_{2}\right)$ for extraction/fractionation of carotenoids from red paprika. Food Chem 2009; 115: 745752.

[29] Xiao X-H, Wang J-X, Wang G, Wang J-Y, Li G-K. Evaluation of vacuum microwaveassisted extraction technique for the extraction of antioxidants from plant samples. J Chromatogr A 2009; 1216: 8867-8873.

[30] Wang J-X, Xiao X-H, Li G-K. Study of vacuum microwave-assisted extraction of polyphenolic compounds and pigment from Chinese herbs. J Chromatogr A 2008;1198-1199:45-53.

[31] Cravotto G, Boffa L, Mantegna S, Perego P, Avogadro M, Cintas P. Improved extraction of vegetable oils under high-intensity ultrasound and/or microwaves. Ultrason Sonochem 2008; 15: 898-902.

[32] Lee J-Y, Yoo C, Jun S-Y, Ahn C-Y, Oh H-M. Comparison of several methods for effective lipid extraction from microalgae. Bioresour Technol 2010; 101: S75-S77.

[33] Choi SK, Kim JH, Park YS, Kim YJ, Chang HI. An efficient method for the extraction of astaxanthin from the red yeast Xanthophyllomyces dendrorhous. J Microbiol Biotechnol 2007; 17: 847-852.

[34] Csiktusnádi Kiss GA, Forgács E, Cserháti T, Mota T, Morais H, Ramos A. Optimisation of the microwave-assisted extraction of pigments from paprika (Capsicum annuum L.) powders. J Chromatogr A 2000; 889: 41-49.

[35] Abramson L, Wirick S, Lee C, Jacobsen C, Brandes JA. The use of soft X-ray spectromicroscopy to investigate the distribution and composition of organic matter in a diatom frustule and a biomimetic analog. Deep-Sea Res (2 Top Stud Oceanogr) 2009; 56: 1369-1380.

[36] Parsons TR, Maita Y, Lalli CM. A manual of chemical and biological methods for seawater analysis. Oxford: Pergamon Press; 1984. p. 173.

[37] Strickland JDH, Parsons TR. A practical handbook of seawater analysis. Bull. Fish. Res. Bd. Can; 1972. p. 310.

[38] Jeffrey SW, Hallegraeff GM. Chlase distribution in ten classes of phytoplankton : a problem for chl analysis. Mar Ecol Prog Ser 1987; 35: 293-304.

[39] Barrett J, Jeffrey SW. A note on the occurrence of chlase in marine algae. J Exp Mar Biol Ecol 1971; 7: 255-262. 
[40] Fratianni A, Cinquanta L, Panfili G. Degradation of carotenoids in orange juice during microwave heating. LWT Food Sci Technol 2010; In Press, Corrected Proof. doi:10.1016/j.Iwt.2010.01.011

[41] Lee HS, Coates GA. Effect of thermal pasteurization on Valencia orange juice color and pigments. Lebensm Wiss Technol 2003; 36: 153-156.

[42] Sun Y, Ma G, Ye X, Kakuda Y, Meng R. Stability of all-trans- $\beta$-carotene under ultrasound treatment in a model system: Effects of different factors, kinetics and newly formed compounds. Ultrason Sonochem 2010; 17(4): 654-661. 